\title{
Comparison of Environmental and Life Cycle Impact of a Switched Reluctance Motor Drive and Inverter-Fed Induction Motor Drives
}

\author{
P. Andrada, B. Blanqué, E. Martínez, J.I. Perat, J.A. Sánchez, M. Torrent \\ Grup d'Accionaments Elèctrics amb Commutació Electrònica (GAECE) \\ EPS d'Enginyeria de Vilanova i la Geltrú, Departament d'Enginyeria Elèctrica \\ Universitat Politècnica de Catalunya (UPC) \\ Avinguda Victor Balaguer, s/n, 08800 Vilanova i la Geltrú, Barcelona, Spain \\ Tel./fax:+0034 938967732, e-mail: andrada@ ee.upc.edu
}

\begin{abstract}
This paper compares the environmental and life cycle impact of one switched reluctance motor (SRM) drive and two inverter-fed induction motor (IM) drives. The study was carried out according to the Directive on the Ecodesign of Energy-Using Products (EuP 2005/32/EC) and following the Methodology for the Ecodesign of Energy-Using Products (MEEUP). The following base-case models were used: an IM (Eff3), an IM (Eff1) and an 8/6 SRM. All of these base-case models are rated at $1.5 \mathrm{~kW}$ of output power and are considered to be representative of the low-power range. The analysis shows that SRM drive has a lower environmental impact than the IM drives and offers a high savings potential, comparable to, or even greater than that of the IM (Eff1) in the use phase.
\end{abstract}

\section{Key words}

Life cycle assessment, environmental, efficiency, induction motor, switched-reluctance motors.

\section{Introduction}

Energy-efficient motors can save enormous quantities of energy and reduce emissions of greenhouse gases [1-2]. It is no longer enough to take into account the efficiency of an electric motor; all life cycle costs (i.e. production, use and disposal) must be considered. The Directive on the Ecodesign of Energy-Using Products (EuP 2005/32/EC) establishes requirements that certain energy-using products must fulfill in order to be placed on the market and/or put into service. The Methodology for the Ecodesign of Energy-Using Products (MEEUP) [3] was developed to determine whether, and to what extent, a product fulfills the criteria that would make it eligible under the Directive. Although energy-efficient motors are usually associated with three-phase induction motors (IMs) [4], switched-reluctance motors (SRMs) have been vying for a place in the electric motor market thanks to their simple, rugged construction, their faulttolerance capability and their high efficiency [5]. This paper compares the environmental and life cycle impact of one SRM drive and two inverter-fed IM drives. The study was carried out according to EuP 2005/32/EC and following the MEEUP methodology.

\section{Description of the drives}

Three base-case models were adopted as representative of the low-power range of variable-speed drives (VSDs): one SRM drive and two inverter-fed IM drives.

The SRM was an 8/6 SRM, $300 \mathrm{~V}$, with $1.5 \mathrm{~kW}$ of output power and an IEC-90 frame (see Fig. 1). The SRM was designed using the FLUX 2D FEM package; Fig. 2 shows flux plots in aligned and unaligned positions. In addition, several ecodesign criteria were taken into account:

- The number of materials should be reduced.

- The number of non-recyclable parts (i.e. plastics) should be minimized.

- The motor should be easily assembled and disassembled.

- The windings should be easy to remove.

The SRM was built by the authors but has not yet been commercialized [6].

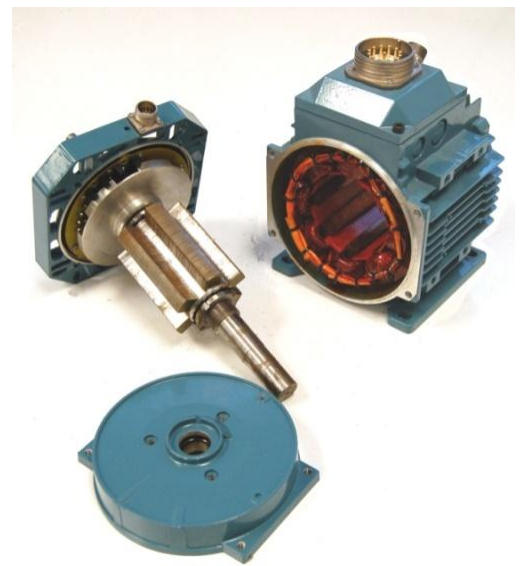

Fig. 1. Photograph of the disassembled $8 / 6$ SRM 

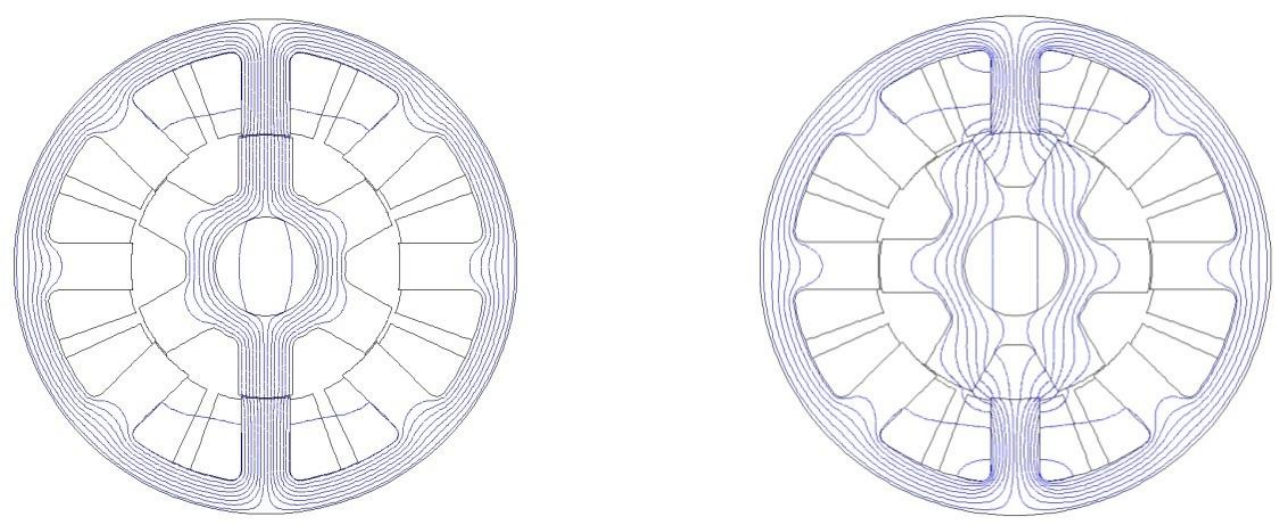

Fig. 2. Flux plots of the $8 / 6$ SRM in aligned (left) and unaligned (right) positions obtained using the FLUX 2D FEM package

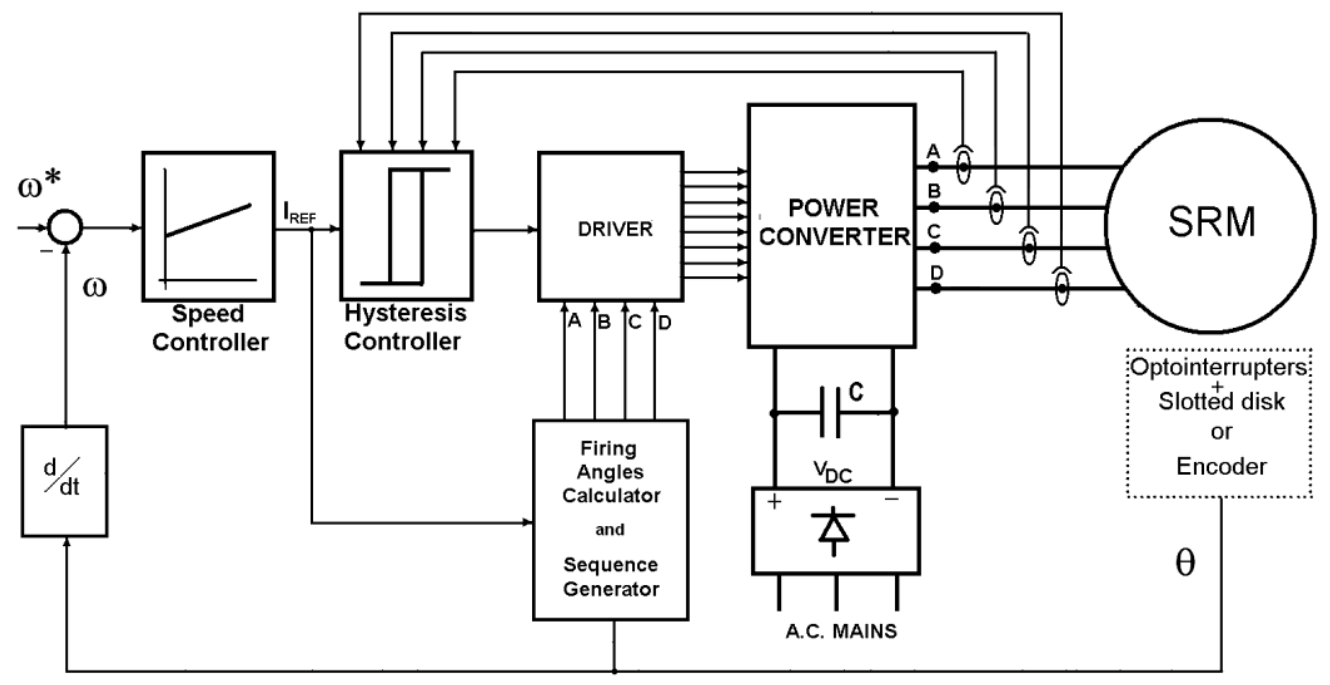

Fig. 3. Schematic diagram of the SRM drive

The SRM was controlled using the drive depicted in Fig. 3. The power converter is a four phases, half asymmetric bridge or classic converter, with two IGBTs and two fast diodes per phase. The rotor position is determined by means of an encoder or an ensemble formed by a slotted disk and three opto-interrupters placed inside the SRM. The speed controller, a proportional-integral (PI) controller, generates a current command based on the error between the reference speed and the motor speed. The current in the appropriate phase is regulated at the reference current by hysteresis control. The firing angle calculator computes the turn-on and turn-off angles at every instant, taking into account the actual speed and reference current [7].

The IMs were four poles, 230/400 V, $1.5 \mathrm{~kW}$ of output power and IEC-90 frame. The first was an Eff3 and the second an Eff1 (for more details, see Appendix). Both motors were driven by an inverter-fed vector control in closed loop through an incremental encoder. Both the motors and the vector-control equipment are commercially available.

A full description of the base case requires an inventory of the products used, including the packing (bill of materials). It also requires records of the energy and other resources consumed during the production phase and the use phase. Finally, it requires a scenario for recycling, re- use and disposal. Table I, the bill of materials, shows all of the products used. Table II shows the inputs of the use phase: lifetime, global efficiency and operating hours. Global efficiency versus torque was obtained experimentally and is shown in Fig. 4 for the IM (Eff3) drive, in Fig. 5 for the IM (Eff1) drive, and in Fig. 6 for the SRM drive.

\section{Environmental impact and life cycle costs}

Table III shows the life cycle impact of the drives, considering a lifetime of 12 years, 4000 hours per year of operation, and an average load factor of $60 \%$. The life cycle indicators are classified in three groups: main indicators, emissions to air, and emissions to water. It is important to point out that in this table a loss based impact analysis is presented because electric drives are considered as energy converters and not as end use devices therefore only losses are consumed inside the drives, with the remaining energy being transmitted as mechanical power. Table IV summarizes the life cycle costs (LCC). The product price list of the SRM is just an estimation. The electrical energy costs are computed considering 4000 hours of operation per year and the price of electricity in Spain. Repair and maintenance costs were considered negligible because motors smaller than $5 \mathrm{~kW}$ are not, normally, repaired upon failure. 
TABLE I. Bill of materials

\begin{tabular}{|c|c|c|c|}
\hline Material (kg) & IM (Eff3) & IM (Eff1) & 8/6 SRM \\
\hline Electrical steel & 7.84 & 8.65 & 7.46 \\
\hline Other steel & 2.18 & 1.73 & 1.50 \\
\hline Aluminum & 5.13 & 5.28 & 4.48 \\
\hline Copper & 1.80 & 2.05 & 2.50 \\
\hline Insulation material & 0.07 & 0.07 & 0.01 \\
\hline Impregnation resin & 0.44 & 0.44 & 0.20 \\
\hline Paint & 0.15 & 0.15 & 0.06 \\
\hline Plastics & 0.49 & 0.49 & 0.53 \\
\hline Electronics & 0.36 & 0.36 & 0.36 \\
\hline Packing material & 1.50 & 1.50 & 1.50 \\
\hline
\end{tabular}

TABLE II. Use phase

\begin{tabular}{|c|c|c|c|}
\hline Variable & IM (Eff3) & IM (Eff1) & 8/6 SRM \\
\hline Lifetime (years) & 12 & 12 & 12 \\
\hline Global efficiency (\%) & 75.1 & 77.5 & 83.6 \\
\hline Operating hours & 4000 & 4000 & 4000 \\
\hline
\end{tabular}

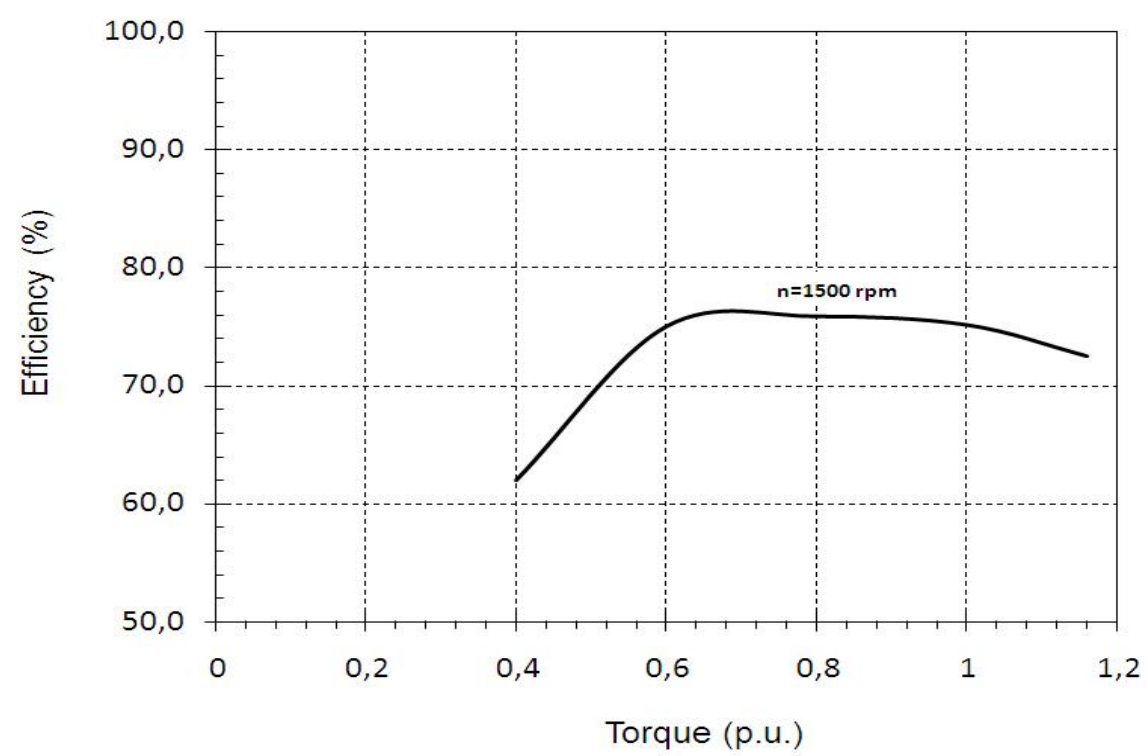

Fig. 4. Global efficiency vs. torque for the IM (Eff3) drive

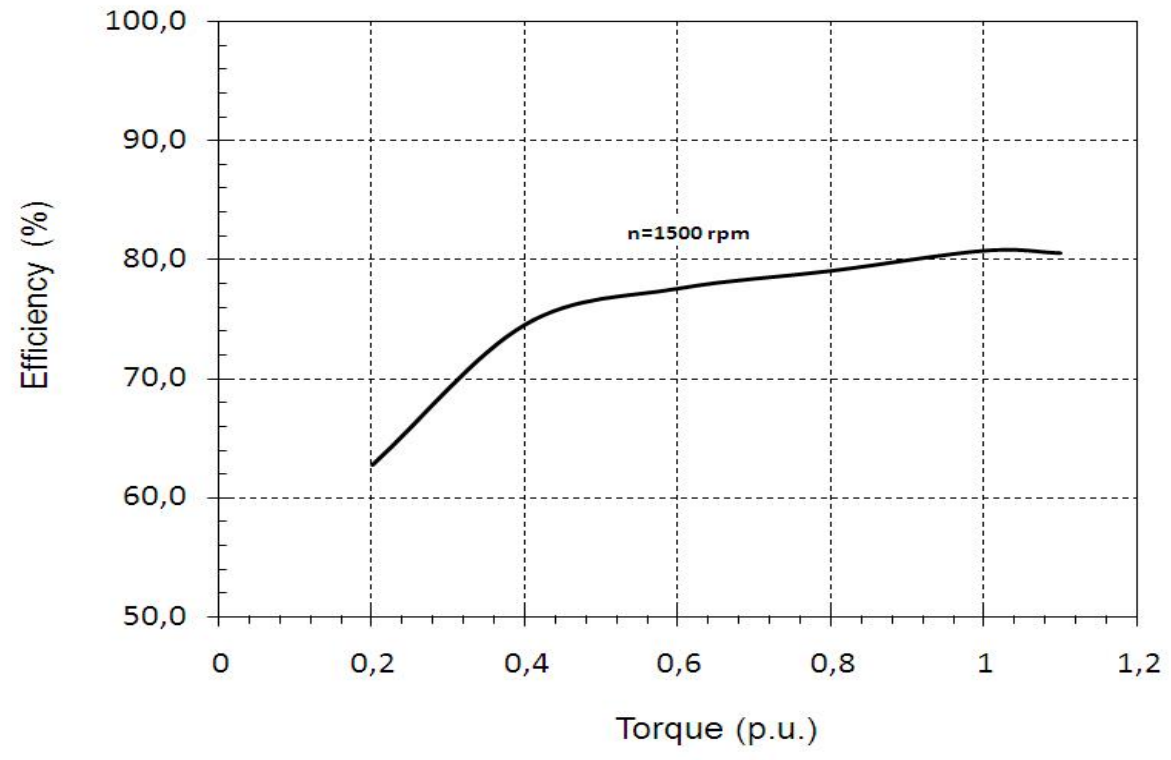

Fig. 5. Global efficiency vs. torque for the IM (Eff1) drive 


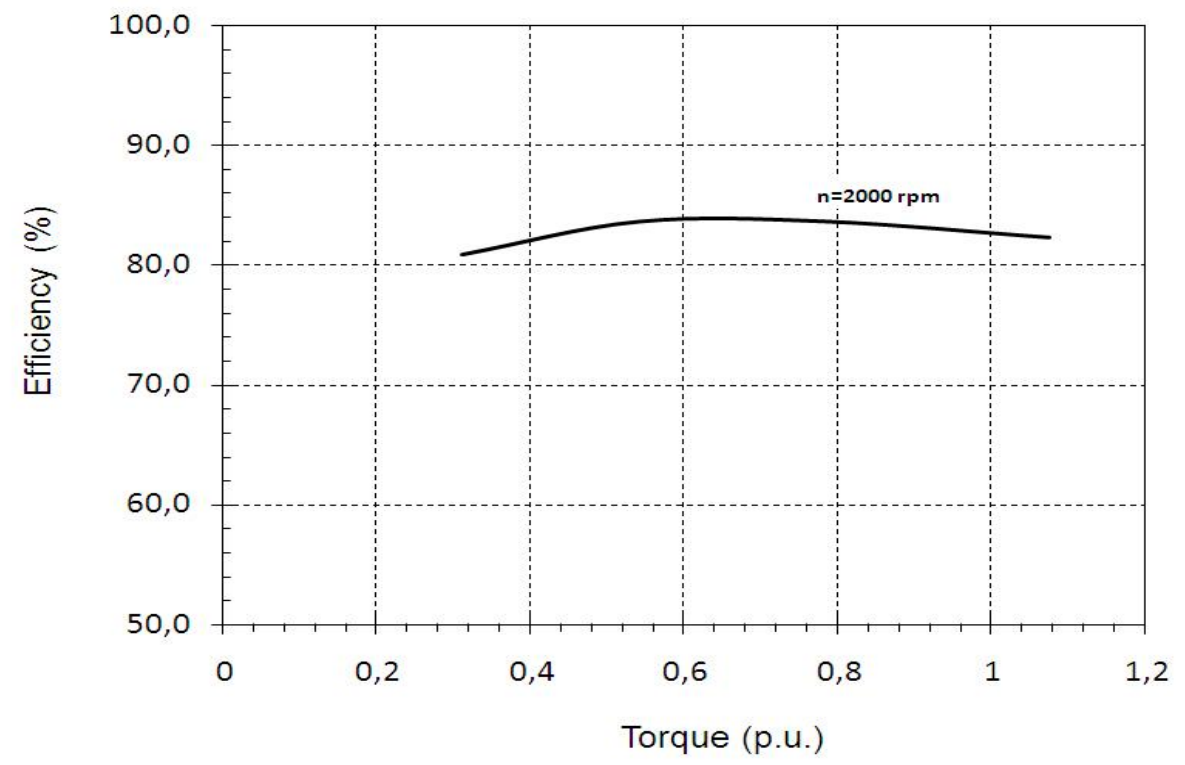

Fig. 6. Global efficiency vs. torque for the $8 / 6$ SRM drive

TABLE III. Environmental impact for each product (drive)

\begin{tabular}{|c|c|c|c|}
\hline Main indicators & IM (Eff3) & IM (Eff1) & 8/6 SRM \\
\hline Total energy GER $^{(1)}(\mathrm{MJ})$ & 153052 & 133983 & 91511 \\
\hline Of which, electricity (in primary MJ) $^{\text {Water process (l) }}$ & 151022 & 131879 & 89506 \\
\hline Waste, non-hazardous landfill (g) & 10205 & 8928 & 6100 \\
\hline Waste, hazardous incinerated (g) & 233709 & 217846 & 174648 \\
\hline
\end{tabular}

\begin{tabular}{|c|c|c|c|}
\hline Emissions to air & IM (Eff3) & IM (Eff1) & 8/6 SRM \\
\hline Greenhouse gases in GWP100 ${ }^{(2)}\left(\mathrm{kg} \mathrm{CO}_{2} \mathrm{eq}\right)$ & 6736 & 5905 & 4049 \\
\hline Ozone depletion emissions (mg R-11 eq) & \multicolumn{3}{|c|}{ negligible } \\
\hline Acidification potential $\left(\mathrm{g} \mathrm{SO}_{2} \mathrm{eq}\right)$ & 39883 & 35039 & 24226 \\
\hline $\operatorname{VOC}(\mathrm{g})^{(3)}$ & 72 & 65 & 49 \\
\hline Heavy metals (mg Ni eq) & 3013 & 2706 & 1987 \\
\hline Particulate matter $(\mathrm{g})$ & 3813 & 3715 & 3444 \\
\hline Emissions to water & IM Eff3 & IM Eff1 & SRM \\
\hline Heavy metals (mg Hg/20) & 1059 & 941 & 661 \\
\hline Eutrophication $\left(\mathrm{g} \mathrm{PO}_{4}\right)$ & 14 & 14 & 9 \\
\hline
\end{tabular}

(1) Gross energy requirement

(2) Global warming potential

(3) Volatile organic compounds

TABLE IV. LCC for each product (drive)

\begin{tabular}{|c|c|c|c|}
\hline Main indicators & IM (Eff3) & IM (Eff1) & 8/6 SRM \\
\hline Product list price $(€)$ & 123 & 267 & 384 \\
\hline Electrical energy $(€)$ & 1209 & 1055 & 717 \\
\hline Repair and maintenance costs & --- & --- & --- \\
\hline
\end{tabular}

\section{Conclusion}

This paper has compared the environmental and life cycle impact of one 8/6 SRM drive and two IM drives that are considered to be representative of the low-power range. The analysis was carried out according to EuP
2005/32/EC and following the MEEUP methodology. The analysis showed that the SRM drive has a lower environmental impact than the IM drives in all aspects considered. In addition, the SRM drive offers a high savings potential, mainly due to its high efficiency. In the use phase, SRM motors are comparable to, or even superior to, the Eff1 three-phase IMs. Unfortunately, one 
drawback of the MEEUP methodology is that it does not reflect one of the main advantages of SRM-namely, the ease with which its various parts and materials can be separated in the disposal phase.

SRM motors have not yet reached the status of standard commodity products. As a consequence, OEMs, which are mainly interested in a motor's list price since they do not pay for operating costs, do not consider them a good choice [8]. In any event, the production phase of SRM motors must be improved in order to reduce first costs; one clear disadvantage is the large amount of magnetic steel waste generated from punching. However, this will be difficult to achieve if there are very few potential purchasers. Regulatory measures focused on minimum efficiency standards for motors would be a first step towards removing inefficient motors from the market and pushing SRMs to the frontline.

\section{Acknowledgment}

This research was supported by the Spanish Ministry of Education and Science and the European Regional Development Fund (DPI2006-09880).

\section{References}

[1] A.T. de Almeida, F.J.T.E. Ferreira, D. Both. "Technical and Economical Considerations in the Application of Variable-Speed Drives with Electric Motor Systems," IEEE Transactions on Industry Applications, Vol. 41, No. 1, January/February 2005, pp. 188-198.

[2] A. Binder. "Potentials for Energy Savings with Modern Drive Technology: A Survey." SPEDAM 2008, pp. 9095.

[3] http://ec.europa.eu/energy/demand/legislation/eco_design _en.htm

[4] A.T. de Almeida, F.J.T.E. Ferreira, J. Fong, P. Fonseca. "EUP Lot 11 Motors: Final," February 2008.

[5] A. Binder. "Switched Reluctance Drive and Inverter-Fed Induction Machine: A Comparison of Design Parameters and Drive Performance." Electrical Engineering 82, 2000, pp. 239-248.

[6] FLUX User's Manual, www.cedrat.com

[7] E. Martínez, P. Andrada, B. Blanqué, M. Torrent, J.I. Perat, J.A. Sánchez. "Environmental and Life Cycle Cost Analysis of a Switched Reluctance Motor." ICEM 2008, CD-ROM, 6-9 September 2008 , Vilamoura (Portugal).

[8] A.T. de Almeida, P. Fonseca, H. Falkner, P. Bertoldi. "Market Transformation of Energy-Efficient Motor Technologies in the EU." Energy Policy, Vol. 31, 2003, pp. 563-576.

\section{Appendix}

\section{IM nameplate data}

\begin{tabular}{|c|c|c|}
\cline { 2 - 3 } \multicolumn{1}{c|}{} & IM (Eff3) & IM (Eff1) \\
\hline Frame size & $90 \mathrm{~L}$ & $90 \mathrm{~L}$ \\
\hline Power & $1.5 \mathrm{~kW}$ & $1.5 \mathrm{~kW}$ \\
\hline Speed & $1420 \mathrm{rpm}$ & $1440 \mathrm{rpm}$ \\
\hline Voltage & $230 / 400 \mathrm{~V}$ & $230 / 400 \mathrm{~V}$ \\
\hline Current & $6.1 / 3.5 \mathrm{~A}$ & $5.7 / 3.3 \mathrm{~A}$ \\
\hline Power factor & 0.8 & 0.77 \\
\hline IP & IP55 & IP55 \\
\hline Insulation class & $\mathrm{F}$ & $\mathrm{F}$ \\
\hline
\end{tabular}

